\title{
Evidence for co-ordinated changes between vascular endothelial growth factor and nitric oxide synthase III immunoreactivity, the functional status of the thyroid follicles, and the microvascular bed during chronic stimulation by low iodine and propylthiouracyl in old mice
}

\author{
Anne-Catherine Gérard, Valérie Xhenseval, Ides M Colin, Marie-Christine Many and Jean-François Denef \\ Histology Unit, Université Catholique de Louvain, Medical School, Brussels, Belgium \\ (Correspondence should be addressed to J-F Denef, Laboratory of Histology, Catholic University of Louvain, Medical School, Avenue E Mounier 52 UCL \\ 5229,B-1200 Brussels, Belgium; Email: denef@isto.ucl.ac.be)
}

\begin{abstract}
Vasoactive and angiogenic factors are involved in the autocrine/paracrine thyroid regulation of microvascular bed during goiter development.

In the thyroid of old mice, the presence of slowly functioning ('cold') follicles allowed us to study the microvascular regulation of each follicle in correlation with the immunohistochemical expression of vascular endothelial growth factor (VEGF) and nitric oxide synthase III (NOSIII). Mice aged 20 months did or did not receive a goitrogenic treatment (low iodine diet and propylthiouracyl), and their thyroids were processed for light and electron microscopy, and for autoradiography. The relative volumes (Vv) of the capillaries, the number of vessels per follicular area, the mean capillary area and the number of $\left[{ }^{3} \mathrm{H}\right]$ thymidine labeled nuclei were measured separately for 'hot' and 'cold' follicles.

Already in control mice, the capillary bed surrounding 'hot' follicles was significantly larger than that seen around 'cold' follicles, because of larger diameters and twice the number of capillaries. This difference persisted whatever the length of the stimulatory treatment. During this treatment, the $\mathrm{Vv}$ of the capillaries increased to a larger extent around 'hot' follicles than around 'cold' ones. All vascular changes around 'cold' follicles were less extended and the increase in the capillary diameter was delayed.

In control mice, the 'cold' follicles were negative for NOSIII and positive for VEGF while 'hot' follicles were positive for both. During stimulation, all follicles became progressively NOSIII positive.

These data support the concept of 'angio-follicular units' in the thyroid and demonstrate their differential regulation in chronic stimulation during which local secretion of VEGF and NO is clearly involved.
\end{abstract}

European Journal of Endocrinology 142 651-660

\section{Introduction}

Microvascular changes are known to play a key role during tumor growth (1) and goiter development $(2,3)$. The early dilation of capillaries and endothelial cell proliferation that occur before epithelial cell division are hallmarks of morphological changes occurring at the onset of goiter formation $(4,5)$.

The mechanisms of regulation of the vascular changes are not yet understood. Recent evidence suggests that vascular growth factors and vasoactive substances are involved in the regulation of the capillary bed. Expression of vascular endothelial growth factor (VEGF) $(6,7)$, fibroblast growth factor (FGF) $(8-11)$, epidermal growth factor (12), transforming growth factor $\beta$ (TGF- $\beta$ )
(10, 13), endothelin-1 (14, 15) and nitric oxide synthases (NOS) $(16,17)$ have been detected in the thyroid gland. In addition, several in vitro experiments have clearly shown that thyroid cells are able to synthesize and secrete thyrotropin (TSH)-regulated growth factors, such as insulin-like growth factor-I (18), TGF- $\beta$ (19), VEGF (6) and FGF (20).

The thyroid gland is also characterized by morphological and functional heterogeneity. As a rule, central follicles are small and more active than the large peripheral ones. This heterogeneity can be enhanced, leading to the formation of non or poorly functional follicles named hereby 'cold' follicles that can cluster to form 'cold' nodules. The presence of 'cold' follicles in the thyroid gland of old mice makes them a model of nodule 
formation (21-23). These follicles could result from local differences in the functional status of their cells and/or of their microvascular bed. From this point of view, the thyroid could thus be considered as a cluster of 'angio-follicular units' with autocrine/paracrine interactions between follicular and endothelial cells.

To verify the hypothesis that the functional status of thyroid follicles is correlated with changes in the adjacent vasculature, we analyzed the expression of VEGF and NOSIII in relation to follicular and vascular changes in a model of old mice under conditions of either quiescent control or chronic stimulation.

\section{Materials and methods}

\section{Animals and treatments}

Twenty-four C57 black mice, 18-20 months old, were divided into five groups: controls $(n=3)$, iodine deficient (low iodine diet (LID) corresponding to $0.1 \mu \mathrm{g} /$ day, Animalabo, Brussels, Belgium) supplemented with 0.25\% 6-n-propyl-2-thiouracyl (PTU, Sigma, St Louis, MO, USA) for 10 days $(n=3), 16$ days $(n=6), 28$ days $(n=8)$ or 34 days $(n=4)$ followed by LID alone for a further two days. Each animal was injected with $\left[{ }^{3} \mathrm{H}\right]$ thymidine $(30 \mu \mathrm{Ci}$, Amersham International, Amersham, Bucks, UK) one hour before death to analyze the proliferative index by autoradiography. The animals were fed a normal iodine diet ( $1 \mu \mathrm{g} /$ day) from their birth until the onset of the treatment.

In a second experiment, 20 C57 black mice, of similar age, were divided into four groups: control, LID+PTU for 10, 16 or 34 days followed by LID alone for a further two days. They were used to test the presence of VEGF and NOSIII immunoreactivity by immunohistochemistry.

A third experiment was performed with 24 ICR mice, 18-24 months old, to control the reproducibility of the stereological procedures.

\section{Microscopy}

In the first experiment, animals were anesthetized with thiopentane and perfused through a cannula placed in the right ventricle under a pressure of $80 \mathrm{mmHg}$ with saline for $1 \mathrm{~min}$ at $37^{\circ} \mathrm{C}$, and thereafter with paraformaldehyde (4\%)-dextran (3.5\%) in PBS buffer ( $\mathrm{pH} 7.4$ ) for $4 \mathrm{~min}$. One thyroid lobe was carefully dissected and fixed immediately in Bouin Allen solution while the second lobe was left in situ. Each thyroid lobe was weighed immediately after dissection. The perfusion was then continued with a solution of paraformaldehyde (2\%)-glutaraldehyde (2.5\%)-dextran $(3.5 \%)$ in $0.1 \mathrm{~mol} / \mathrm{l}$ cacodylate buffer ( $\mathrm{pH} 7.4$ ) for $5 \mathrm{~min}$. The second lobe was then carefully dissected and immersed in a solution of $2.5 \%$ glutaraldehyde for $1.5 \mathrm{~h}$, rinsed in cacodylate buffer, post-fixed in $1 \%$ osmium tetroxide for $1 \mathrm{~h}$, dehydrated and embedded in LX112 resin (Ladd Research Industries, Burlington, VT, USA). Sections
(0.5 $\mu \mathrm{m}$ thick) were stained with toluidine blue and used for morphometrical analysis. Ultrathin sections were cut and stained with uranyl acetate and lead citrate, and examined with an EM301 electron microscope (Philips, Eindhoven, The Netherlands). Autoradiographies were performed on $1 \mu \mathrm{m}$-thick sections from the Epon embedded lobes as previously described $(4,5)$.

In the second experiment, the first lobe was dissected after anesthesia and rapidly frozen to perform cryostat sections. The animal was then perfused with a solution of paraformaldehyde (4\%)-dextran (3.5\%) in PBS buffer (pH 7.4) for 4 min. The second lobe was carefully dissected and immersed in a solution of $4 \%$ paraformaldehyde for $36 \mathrm{~h}$, dehydrated and embedded in paraffin. Thick $(5 \mu \mathrm{m})$ sections were cut and used for immunohistochemistry, as described below.

\section{Morphometrical analysis}

The morphometrical measurements were performed by point counting according to Weibel et al. (24) on one whole section crossing the center of one lobe, known to be representative of the gland (25). Follicles were ranked as 'cold' or 'hot' depending on the aspect of their epithelium and their colloid, according to previous autoradiography studies (21-23). Variation of the microscopical aspects correlated with various functional states. 'Cold' follicles are lined by a flat epithelium, and the lumen is filled with a dense colloid whereas 'hot' follicles are lined by a cuboidal epithelium and the lumen is filled with a moderately dense colloid.

For each follicle, the relative volumes $(\mathrm{Vv})$ of epithelium, follicular lumen and capillaries in close contact with the thyrocytes were measured separately. In addition, the number of sections of capillaries in relation with each follicle was counted. Capillary sections in contact with two adjacent follicles were taken into account for each follicle. The mean area of capillaries' profiles was also calculated (noted mean capillary area) based on the following formula $\mathrm{A}_{(\mathrm{I})}=\mathrm{P}_{(\mathrm{I})} \cdot 3 / 2 . \mathrm{Z}^{2}(24)$ in which $\mathrm{P}$ is the number of points of the test lattice overlaying the capillaries and $\mathrm{Z}$ the distance between two points of this lattice.

Data were then computed separately for each 'cold' and 'hot' follicle. Follicles with an intermediary aspect were excluded from the morphometrical analysis.

\section{Autoradiographic measurements}

The number of $\left[{ }^{3} \mathrm{H}\right]$ thymidine labeled nuclei in epithelial, endothelial and interstitial cells was recorded for each follicle and computed separately according to their functional aspects.

\section{Statistical analysis}

The statistical difference between 'cold' and 'hot' follicles within the same group and between groups 
Table 1 Percentage of 'hot', 'cold' and 'intermediary' follicles in groups undergoing different treatment regimes. Results are expressed as mean percentages \pm S.E.M.

\begin{tabular}{lccccc}
\hline & & \multicolumn{4}{c}{ lodine-deficient diet } \\
\cline { 3 - 5 } Follicles & No stimulation & 12 days & 18 days & 30 days & 36 days \\
\hline 'Hot' & $51.9 \% \pm 7.8$ & $48.5 \% \pm 1.4$ & $70.3 \% \pm 6.7^{+}$ & $75.7 \% \pm 3.7^{++}$ & $74.2 \pm 4.5^{+}$ \\
'Cold' & $39.3 \% \pm 9.4^{*}$ & $40.1 \% \pm 2.8^{*}$ & $18.5 \% \pm 4.6^{* * *+}$ & $18.9 \% \pm 2.8^{* * *++}$ & $20.7 \% \pm 5.3^{* * *+}$ \\
'Intermediary' & $8.7 \% \pm 4.3^{* *}$ & $11.3 \% \pm 1.7^{* * *}$ & $11.2 \% \pm 2.1^{* * *}$ & $5.3 \% \pm 2.5^{* * *}$ & $5.1 \% \pm 1.9^{* * *}$ \\
\hline
\end{tabular}

${ }^{*} P<0.05,{ }^{* *} P<0.01,{ }^{* *} P<0.001$, compared with 'hot' follicles with similar treatment. ${ }^{+} P<0.05,{ }^{++} P<0.01$, compared with the control (no stimulation) of the same type of follicle.

was tested by two-way analysis of variance (ANOVA2) followed by Fisher or Dunnett tests, and by a MannWhitney test for the mitosis analysis.

\section{Immunohistochemistry}

Tissue sections were dewaxed and rehydrated. After washing with phosphate-buffered saline supplemented with $1 \%$ bovine serum albumin (BSA, ICN, Costa Mesa, CA, USA) (PBS-BSA), the sections were incubated in a solution containing normal rabbit or goat serum (ABC Perox kit, Vector Labs, Burlingame, CA, USA) for $30 \mathrm{~min}$ at room temperature. A polyclonal affinity-purified antimouse VEGF antibody (Santa Cruz Biotechnology, Santa Cruz, CA, USA) or a polyclonal affinity-purified antiNOSIII antibody (Transduction Laboratories, Lexington, KY, USA) was then applied at a dilution of $1 / 200$ (VEGF) or $1 / 600$ (NOSIII) for $1 \mathrm{~h}$ at room temperature. After two washes with PBS-BSA, the antibody binding was detected using the $\mathrm{ABC}$ Perox kit. The peroxidase activity was revealed by the DAB (3-3'-diaminobenzidine tetrahydrochloride (Aldrich, Bornem, Belgium))$\mathrm{H}_{2} \mathrm{O}_{2}$ reaction. The staining was enhanced by incubation in a solution of $0.5 \% \mathrm{CuSO}_{4}$ in saline for $15 \mathrm{~min}$. Sections were counterstained with Mayer's hematoxylin, rinsed, dehydrated and mounted in DPX (BDH, Poole, Dorset, UK).

Several negative controls were performed: absence of the first antibody for NOSIII and immunoneutralization with the peptide for the anti-VEGF antibody (incubation with peptide in excess for $2 \mathrm{~h}$ before immunostaining). Control staining was also performed with or without endogenous peroxidase inhibition.

\section{Results}

\section{Morphology of the glands}

In the glands of control animals, a mixture of 'hot' (Fig. 1A) and 'cold' follicles (Fig. 1B) was observed. The colloid of some 'cold' follicles had a dual aspect: the very dense periphery lined a pale core (Fig. 1B). The epithelial layer of some follicles, called 'intermediary' consisted of cubical cells separated by flat cells (Fig. 1C).

In iodine-deficient animals (Fig. 1D), all 'hot' follicles were hypertrophic, their epithelia were columnar and their follicular lumina were reduced in size. Blood capillaries located around those follicles were dilated. In contrast, 'cold' follicles were poorly responsive to the treatment. At least after short periods of stimulation, the epithelium remained flat and the lumen was still filled with a dense colloid. Vascular changes around these 'cold' follicles were rarely observed.

The epithelial cells of capillaries adjacent to 'hot' and 'cold' follicles had a similar aspect in electron microscopy (Fig. 1E): they contained fenestrations (inset) and transcytotic vesicles. However, there was no fenestration on the side opposite to the follicles.

\section{Quantitative results}

Thyroid weight During iodine deficiency, the weight of the thyroids was slightly but not significantly increased even at day 30. The mean weight values were $6.9 \pm 0.6 \mathrm{mg}$ in controls and $8.4 \pm 0.7 \mathrm{mg}$ after 30 days of treatment.

Follicular parameters (Fig. 2) In controls, the $\mathrm{Vv}$ of the follicular lumina was significantly $(P<0.001)$ smaller in 'hot' follicles than that observed in 'cold' follicles. This difference was observed in all experimental groups.

In controls, the proportion of 'hot' follicles (Table 1) was slightly but not significantly higher than that of 'cold' follicles $(51.9 \% \pm 7.8$ vs $39.3 \% \pm 9.4)$. During iodine deficiency, the proportion increased to reach $74.2 \% \pm 4.5(P<0.05)$ at day 36 of treatment.

The Vv of the follicular lumina of the 'hot' follicles was reduced during stimulation $(0.43 \pm 0.02$ in controls vs $0.09 \pm 0.01$ at day 36 of treatment, $P<0.001$ ). It was also slightly, but significantly, reduced in 'cold' follicles $(0.77 \pm 0.02$ at day 36 of treatment vs $0.83 \pm 0.01$ in controls, $P<0.01)$.

\section{Vascular parameters}

Relative volume of the capillaries (Fig. 3A) In control animals, the $\mathrm{Vv}$ of capillaries surrounding 'hot' follicles was significantly larger and represented twice the value observed around 'cold' follicles.

During chronic stimulation, the $\mathrm{Vv}$ of capillaries 

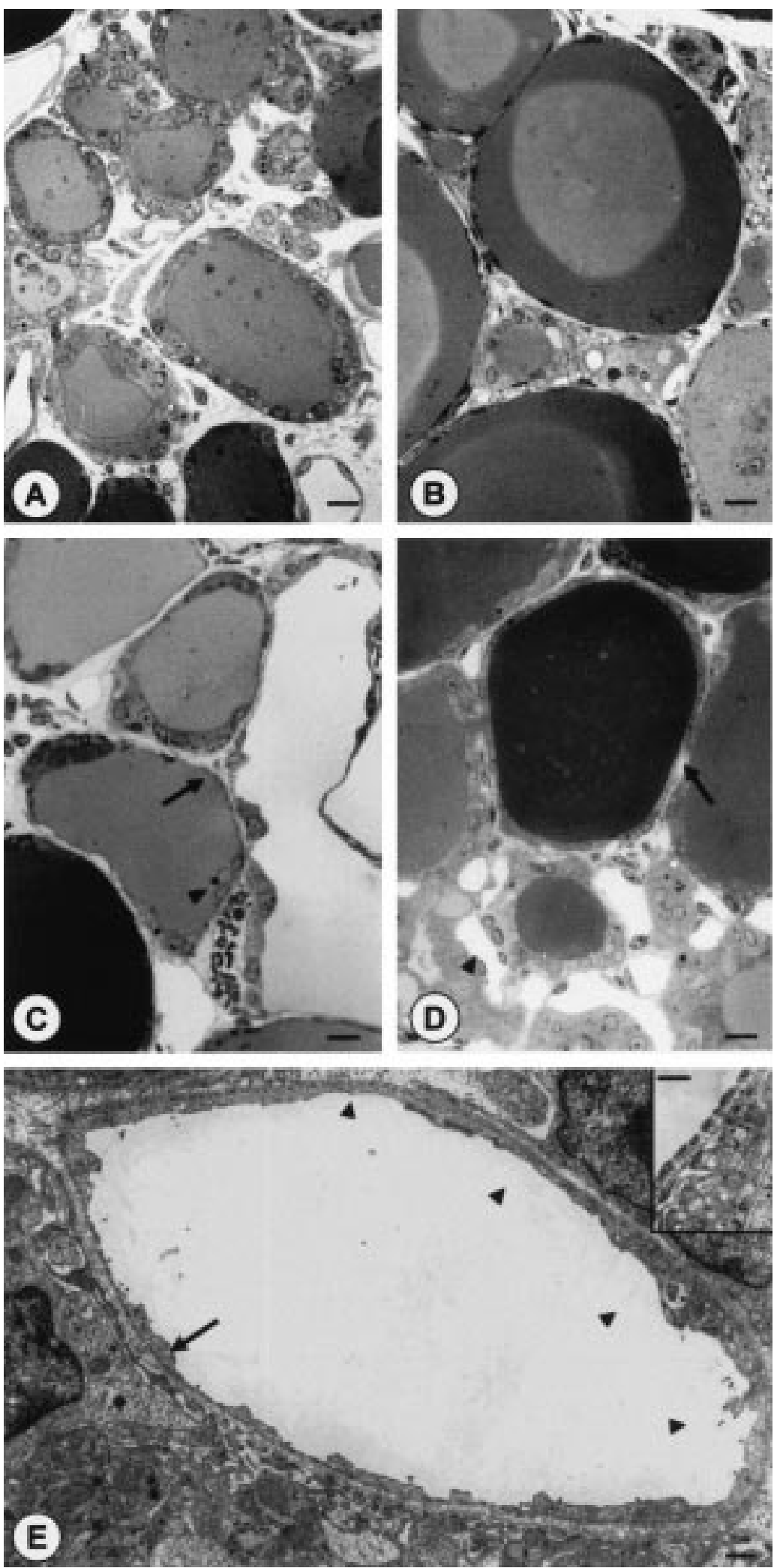

Figure 1 Morphological aspects of thyroid glands of aged mice in light $(A, B, C, D)$ and electron $(E)$ microscopy. $(A, B, C)$ Thyroids of control mice. (A) The epithelium of 'hot' follicles is cubical and the colloid moderately dense. (Scale bar $=10 \mu \mathrm{m}$.) (B) The epithelium of 'cold' follicles is flat and the colloid is dense. Note the frequent bicolor aspect of the colloids. (Scale bar $=10 \mu \mathrm{m}$.)

(C) The aspect of some follicles is intermediary between those of 'cold' and 'hot' follicles: the epithelium is in part flat (arrow) and in part cubical (arrowhead). (Scale $\mathrm{bar}=10 \mu \mathrm{m}$.) (D) Thyroid from an iodinedeficient animal. 'Hot' follicles have a columnar epithelium and their blood capillaries are dilated (arrowhead) while the epithelium of the 'cold' follicles is still flat and the capillaries are not dilated (arrow). (Scale bar $=10 \mu \mathrm{m}$.) (E) Electron microscopy of a capillary close to a thyroid follicle in a control mouse. Note that transcytotic vesicles (arrow) and fenestrations (inset; scale bar $=0.5 \mu \mathrm{m}$ ) are present on the face in contact with the follicle but not present in the endothelial cytoplasm facing the interstitial tissue (arrowheads). (Scale bar $=0.5 \mu \mathrm{m}$.) 


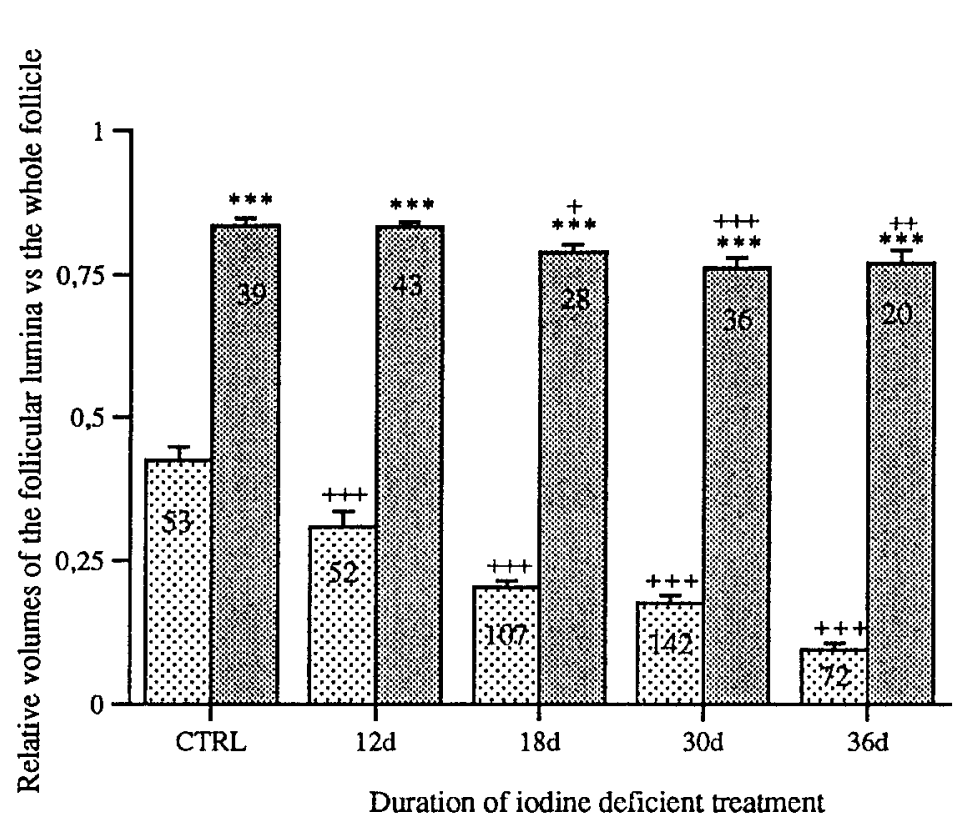

Figure 2 Relative volumes of the follicular lumina with respect to whole follicles in mice receiving LID+PTU for different times. The results are expressed as means \pm S.E.M. CTRL $=$ control mice. ${ }^{* * *} P<0.001$, 'cold' follicles compared with 'hot' follicles with similar treatment. ${ }^{+} P<0.05,{ }^{++} P<0.01,{ }^{++} P<0.001$, compared with the control of the same type of follicle. The numbers in the columns are the numbers of follicles.

surrounding 'hot' follicles increased progressively from $0.2 \pm 0.01$ in controls to $0.43 \pm 0.01$ at day 30 of treatment $(P<0.001)$; after the 30th day of treatment the values leveled off.

The Vv of blood capillaries surrounding 'cold' follicles was also increased, but to a significantly smaller extent than that observed around 'hot' follicles. As a result, the $\mathrm{Vv}$ of vessels around 'hot' follicles increased by 2.7 times compared with 'cold' follicles at 36 days.

Number of capillaries per follicular area (Fig. 3B)

In controls, the number of capillary profiles around 'hot' follicles was significantly higher than that observed around 'cold' follicles $(0.67 \pm 0.04$ vs $0.39 \pm 0.03$, $P<0.001)$. After 12 days, it was significantly reduced around 'hot' follicles. Except at day 12, there was no significant change around 'cold' follicles during the whole treatment.

Mean capillary area (Fig. 3C)

Around 'hot' follicles, the mean capillary area progressively increased until day 18 of treatment (248 \pm $14 \mu \mathrm{m}^{2}$ vs $63.2 \pm 6.3 \mu \mathrm{m}^{2}$ in the controls, $\left.P<0.001\right)$, after which the values leveled off without significant changes.

Around 'cold' follicles, the increase in the capillary area was delayed and it became significant from day 18 only $\left(70.1 \pm 6.7 \mu \mathrm{m}^{2}\right.$ vs $\left.37 \pm 5 \mu \mathrm{m}^{2}, P<0.001\right)$, thereafter remaining constant.

Whatever the length of treatment, the mean capillary area measured around 'cold' follicles remained significantly smaller than that measured around 'hot' follicles.

Cellular proliferation The percentage of total labeled nuclei (Fig. 4A) was low in both 'cold' and 'hot' follicles in control and treated animals. However, it was higher in 'hot' than in 'cold' follicles, the difference being significant only at day $12(P<0.01)$ and day 18 $(P<0.001)$ of treatment. In 'hot' follicles, the total proportion of labeled nuclei was below $0.5 \%$ in control animals and reached a maximum $(1.8 \%, P<0.001)$ at day 18 , thereafter declining to control values at day 36 . No labeled nuclei were observed in 'cold' follicles of control animals. However, their number increased to reach a peak (below 1\%) at day 30 of treatment $(P<0.01)$

The percentage of labeled follicular nuclei (Fig. 4B) was 2 to 3 times higher in 'hot' than in 'cold' follicles at day $12(P<0.05)$ and day $18(P<0.05)$. In 'hot' follicles, the percentage increased progressively to a maximal value at day $18(1.6 \%, P<0.01)$. In 'cold' follicles, a similar trend was observed but the percentage of labeled nuclei remained below $1 \%$.

The percentage of labeled endothelial nuclei (Fig. 4C) increased during iodine deficiency, but to a lesser extent in capillaries surrounding 'cold' follicles than in those surrounding 'hot' follicles. However, this difference was significant only at day $12(P<0.05)$ and day 18 $(P<0.01)$. The proportion of labeled endothelial nuclei around 'hot' follicles was maximal at day 18 (2.3\% vs 


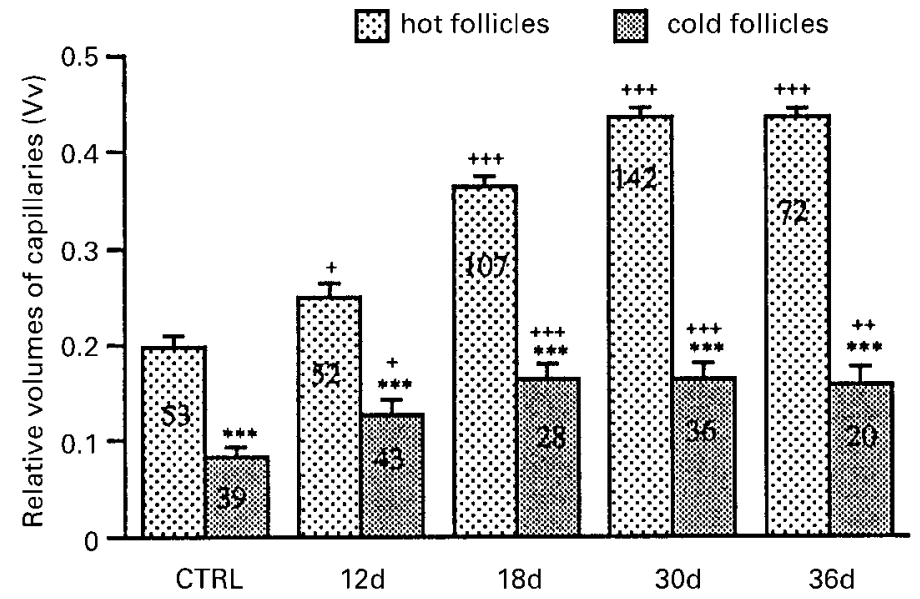

B

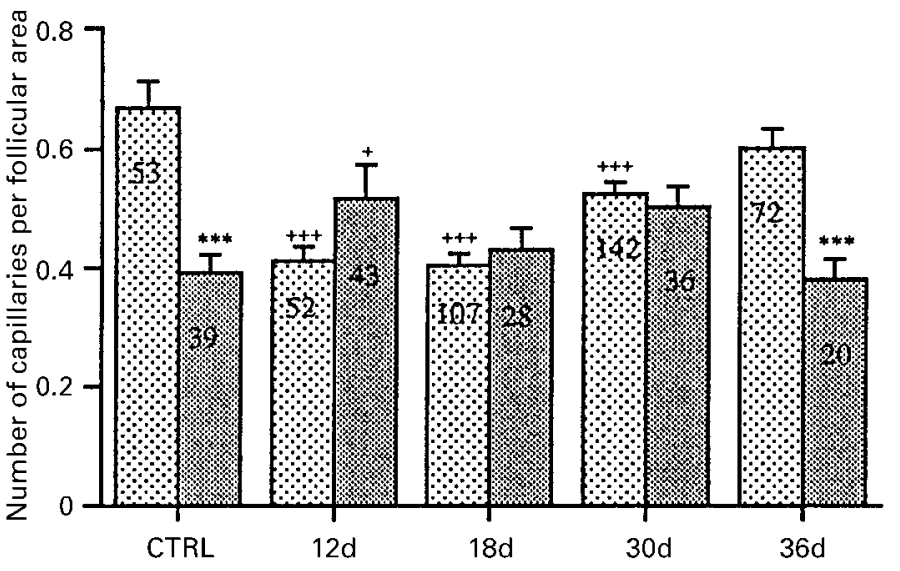

C

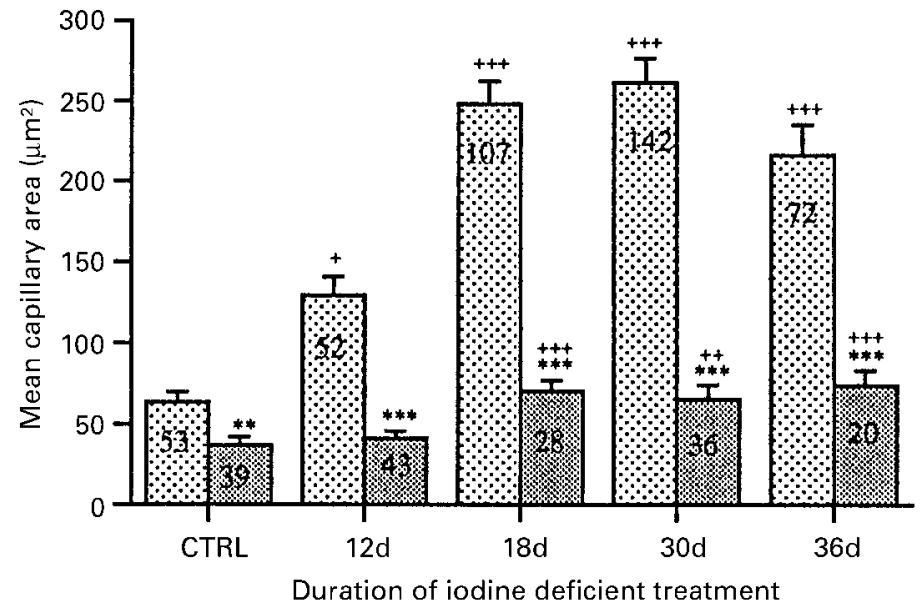

Figure 3 Vascular changes during iodine deficiency. (A) Relative volumes of the vessels. (B) Number of vessels per follicular area. (C) Mean capillary area $\left(\mu \mathrm{m}^{2}\right)$. Results are expressed as means \pm S.E.M. CTRL $=$ control mice. ${ }^{*} P<0.05,{ }^{* *} P<0.01$, ${ }^{* * *} P<0.001$, 'cold' follicles compared with 'hot' follicles with similar treatment. ${ }^{+} P<0.05,{ }^{++} P<0.01,{ }^{+++} P<0.001$, compared with the control of the same type of follicle. The numbers in the columns are the numbers of follicles.
$0 \%$ in controls, $P<0.001)$ and returned to $0.5 \%$ at day 36 .

\section{Immunohistochemistry}

VEGF In the control animals, we detected an immunoreactivity for VEGF in follicular cells of both types of follicles (Fig. 5A). At day 12, the staining was also observed in both types of follicles (Fig. 5B). Similar observations were made at days 18 and 36. Nevertheless, the intensity of the staining was decreased at day 36. In all groups, the endothelial cells remained immunohistologically negative.

NOSIII In control animals, NOSIII immunoreactivity was detected in the follicular cells of 'hot' follicles but not in cells of 'cold' follicles (Fig. 5C). At day 12 (Fig. 5D), 


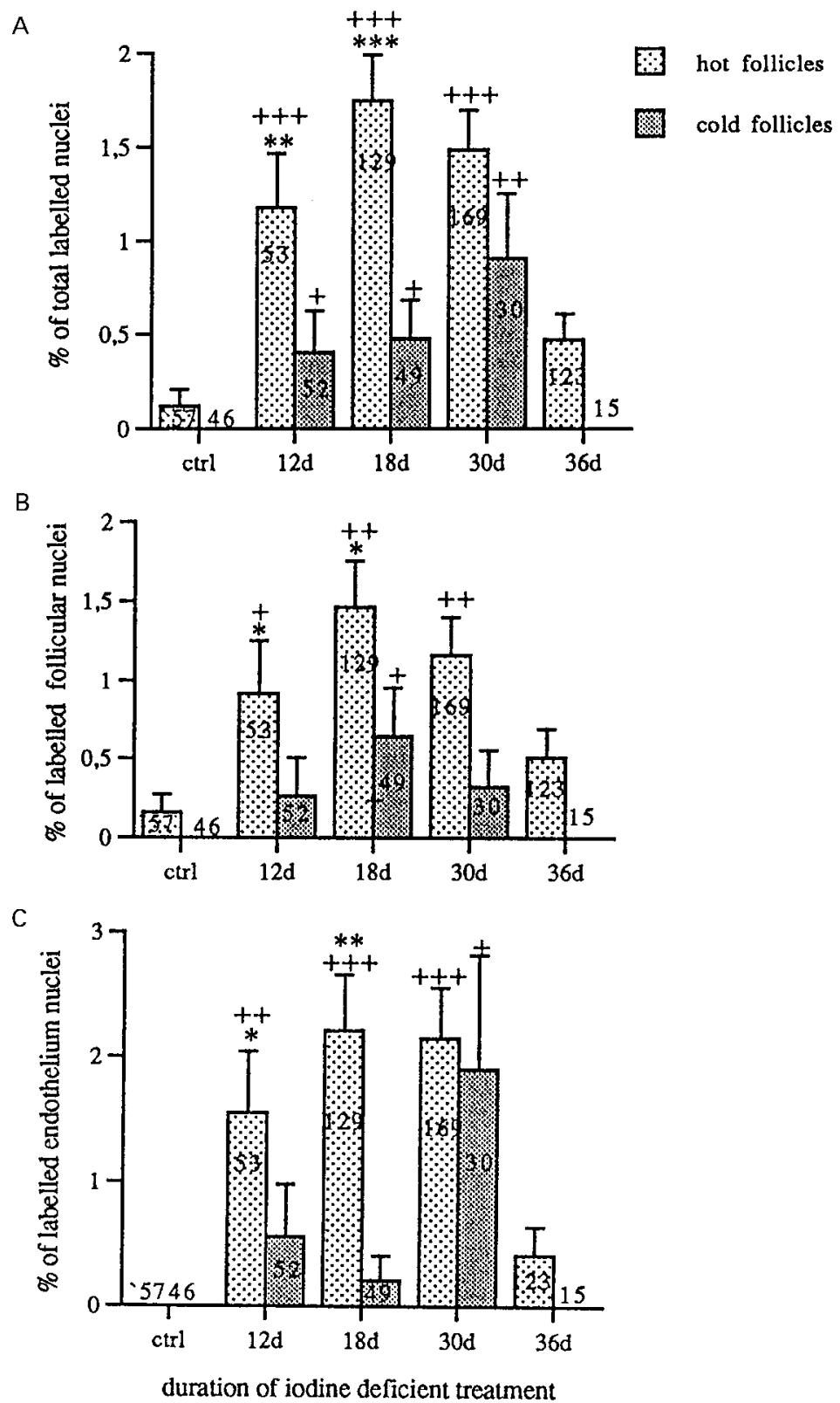

Figure $4\left[{ }^{3} \mathrm{H}\right]$ Thymidine labeling index. (A) Total nuclei. (B) Follicular cells. (C) Endothelial cells. Results are expressed as mean percentage \pm S.E.M. The statistical test used is Mann-Whitney. CTRL $=$ control mice. ${ }^{*} P<0.05,{ }^{* *} P<0.01$, ${ }^{* * *} P<0.001$, 'cold' follicles compared with 'hot' follicles with similar treatment. ${ }^{+} P<0.05,{ }^{++} P<0.01$, ${ }^{+++} P<0.001$, compared with the control of the same type of follicle. The numbers in the columns are the numbers of follicles.

an increasing proportion of cells of 'cold' follicles became positive. In 'hot' follicles, all cells were intensely stained. At days 18 and 36, an intense NOSIII immunoreactivity was detected in all cells of both 'cold' and 'hot' follicles.

In all groups, NOSIII immunoreactivity was detected in the endothelial cells of arteries. The endothelium of capillaries was positive from day 18 of treatment (Fig. 5F).

\section{Third experiment with ICR mice}

As in $\mathrm{C} 57$ black control mice, the $\mathrm{Vv}$ of capillaries in ICR mice was larger around 'hot' than around 'cold' follicles

$(0.23 \pm 0.01$ vs $0.07 \pm 0.005, P<0.001)$. The number of capillaries per follicular area was also reduced $(0.31 \pm 0.02$ vs $0.61 \pm 0.03$ around 'hot' follicles, $P<0.001)$ as well as the mean capillary area $\left(34.7 \pm 2 \mu \mathrm{m}^{2}\right.$ vs $\left.73.7 \pm 4 \mu \mathrm{m}^{2}, P<0.001\right)$.

During chronic stimulation with LID and PTU, the Vv of capillaries was increased around 'hot' follicles from $0.23 \pm 0.01$ in controls to $0.36 \pm 0.01$ at day 36 $(P<0.001)$, as a consequence of an increased mean capillary area $\left(186.3 \pm 9.7 \mu \mathrm{m}^{2}\right.$ at day $\left.36, P<0.001\right)$. The number of capillaries per follicular area decreased from $0.61 \pm 0.03$ in controls to $0.49 \pm 0.02$ at day 36 $(P<0.001)$. Vascular changes around 'cold' follicles were less extended and delayed. 

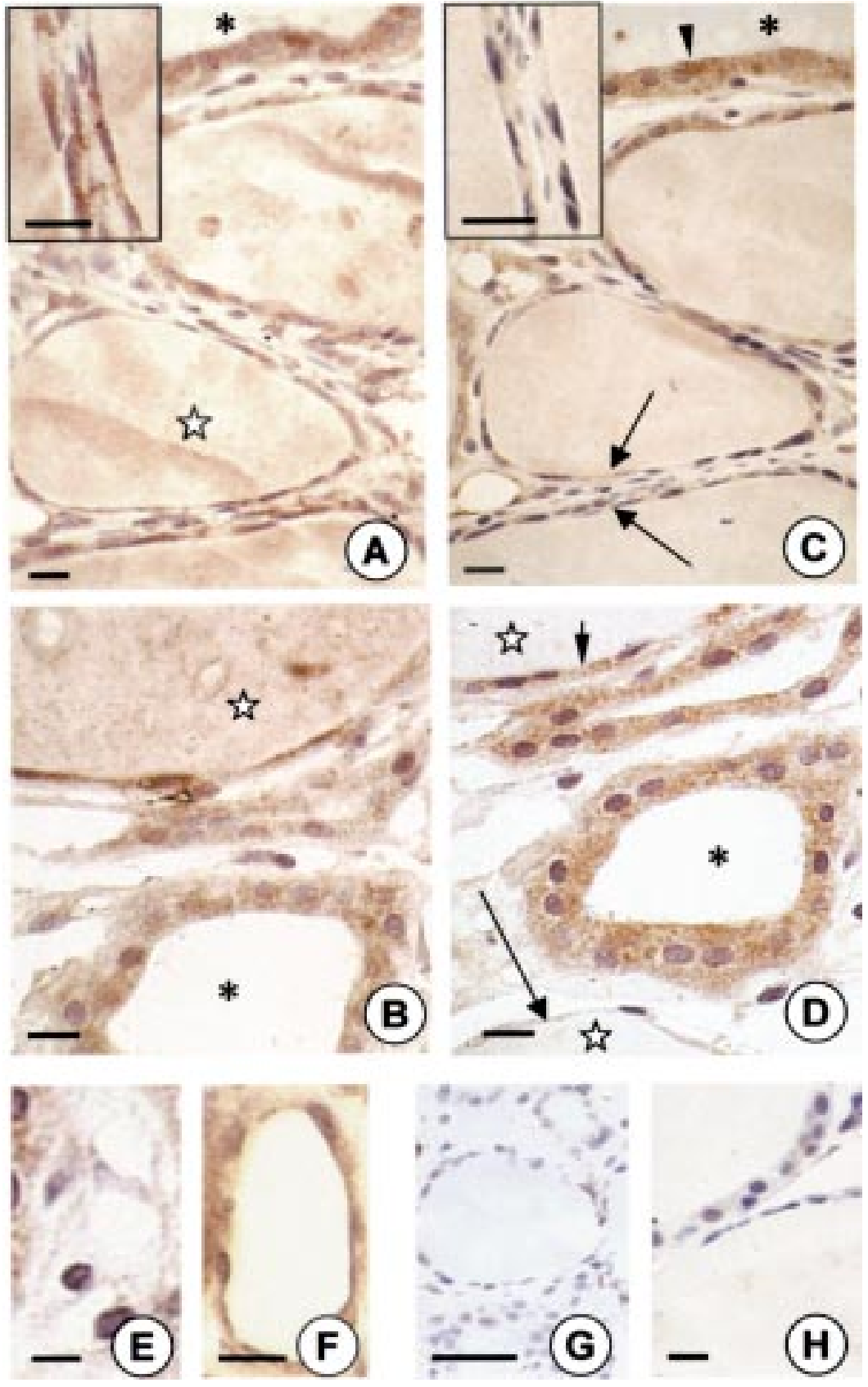

Figure 5 VEGF and NOSIII immunoreactivity. (A, B, G) Immunostaining of VEGF. In the control mice $(A)$ and after 12 days of treatment (B) the follicular cells of both 'cold' $(\star)$ ) and 'hot' $(*)$ follicles are positive. (Scale bar $=13.5 \mu \mathrm{m}$, inset $=14.3 \mu \mathrm{m}$.) The inset shows a higher magnification of 'cold' follicle immunostaining. After immuno-

neutralization with the antigenic peptide $(G)$, the immunoreactivity is absent. (Scale $\mathrm{bar}=44 \mu \mathrm{m}$.) $(\mathrm{C}-\mathrm{F}, \mathrm{H})$ Immunostaining of NOSIII. In the control mice (C) the follicular cells of 'hot' follicles $(*)$ are positive (arrowhead) whereas those of 'cold' follicles remain negative (arrows). The inset shows a higher magnification of 'cold' follicle immunostaining. After 12 days of treatment (D) the 'cold' follicles ( (short arrow) but some are not stained (large arrow). (Scale bar $=13.5 \mu \mathrm{m}$, inset $=14.3 \mu \mathrm{m}$.) The 'hot' follicles $(*)$ are more intensively stained than control ones. Up to day 12 of treatment, the endothelium of the capillaries show no NOSIII immunoreactivity $(E)$ (scale bar $=5 \mu \mathrm{m}$ ) whereas they are positive $(F)$ after 18 days (scale bar $=14.3 \mu \mathrm{m}$ ). If the antibody is replaced by PBS-BSA $(\mathrm{H})($ scale bar $=13.5 \mu \mathrm{m})$ no staining is observed.

\section{Discussion}

Our data show that the changes in the microvascular bed lining thyroid follicles are closely related to the functional aspect of the follicles. Indeed, the $\mathrm{VV}$ of the vessels surrounding active 'hot' follicles are larger than those lining slowly functioning 'cold' follicles. This is the result of increased areas and numbers of capillaries. In addition, changes in mean capillary area in response to chronic thyroid stimulation occur earlier and to a larger extent around 'hot' follicles than around 'cold' follicles.
These changes are correlated with variations in the immunoreactivity for NOSIII and to a much lesser extent for VEGF in the follicular cells.

In the thyroid, the microvasculature plays a crucial role, especially during goiter formation. In the glands of young control animals, a clearly defined capillary network surrounds each follicle and is almost independent of its neighbors. During goiter development, each capillary network is dilated (26). Capillary fusion (27) and endothelial cell proliferation rapidly occur even before epithelial cell proliferation $(4,5,28)$. Different 
local or systemic factors could eventually be involved in the regulation of these processes.

In the thyroid of old mice, two types of follicles coexist ('hot' and 'cold' follicles) (21-23) that reflect the tendency of the thyroid to form multinodular goiter. Based on ${ }^{125}$ I autoradiographic studies (21-23), slowly functioning follicles are characterized by delayed organification and iodine release. They behave on a microscopical scale like 'cold' nodules detected by scintigraphy. Our morphometrical data clearly show that the capillary network surrounding each type of follicle is different and reacts differently upon stimulation. In consequence, the thyroid can be considered as clusters of 'angio-follicular units'. Moreover, the glands of old mice can be used as a model to study the local interactions between endothelial and follicular cells.

In our model, no significant increase in glandular weight was observed during chronic stimulation. This suggests that the glands of old animals react very slowly to a chronic stimulus, altering the different glandular constituents with no changes in weight. This corresponds to previous observations made in young animals under a mild stimulation (4). We took advantage of this slow response to investigate differential changes in the vascular bed in relation to at least two functional follicular states.

The initial cause of 'cold' follicle formation remains unclear. A follicle could be 'cold' because of a defect in the follicular cell function. Indeed, 'cold' follicle formation has been explained by altered endocytosis leading to colloid accumulation (29). In contrast, a follicle could be hypofunctioning due to a reduced vascular supply of TSH or of other tropic substances. Our data do not allow us to distinguish between these hypotheses.

Vascular response to a goitrogenic stimulus involves at least three steps: vasodilation (2), capillary fusion (27) and endothelial cell proliferation $(4,5,28)$. In our study, capillary fusion takes place around 'hot' follicles during chronic stimulation but not around 'cold' follicles. This suggests that capillary fusion is regulated by a local factor. The most likely hypothesis to explain the differential interactions between each follicle and its own capillary network is the presence of local autocrine-paracrine factors. Among them, we chose to investigate two factors known to act on the microvascular bed in different ways: VEGF and NO. VEGF primarily stimulates endothelial cell proliferation, while NO acts mainly as a vasodilator. Its production can be analyzed via the detection of NOSIII, one of the three NOS isoforms (30).

Our data indicate that there was no difference in VEGF immunostaining in follicular cells of both types of follicles. Since VEGF was detected in the 'hot' and 'cold' follicles in control animals i.e. when the endothelial thymidine incorporation was nil, one may suspect that VEGF has another role in this condition. Its role could be related to the presence of fenestrations in the endothelial cells surrounding both types of follicle. Indeed, besides its mitogenic effect, VEGF is known to be a vascular permeability factor (31) responsible for the presence of fenestrations in the endothelium of various organs (choroid plexus, kidney glomeruli) (32), since it induces fenestrations in endothelial cells in vitro (33, 34). Moreover, in our study, the exclusive location of these fenestrations on the side facing the thyroid cells provides a strong argument for a direct microanatomical interplay between follicular and endothelial cells.

Although immunohistochemistry does not give any information about the production or secretion rates of VEGF, its slight increase during chronic stimulation in both 'hot' and 'cold' follicles could be indicative of proliferation of endothelial cells and is in agreement with previous observations suggesting that VEGF plays a role during goiter formation $(6,7)$.

The NOSIII immunoreactivity detected in epithelial cells of 'hot' follicles in control animals in correlation with the larger diameter of capillaries compared with 'cold' follicles, namely when endothelial cell proliferation is nil, suggests a role for NO in vascular tone. The absence of NOSIII immunoreactivity in control 'cold' follicles and its enhanced expression along with the goitrogenic treatment confirms that NOSIII is regulated in vivo in the follicular cells, as previously suggested (16, 17). However, care should be taken in the interpretation: (i) NOSIII is a constitutive enzyme (35) the activity of which is largely modulated by numerous posttranslational changes, including cytosolic calcium concentrations. (ii) Whether NO has an exclusive effect on vasodilatation or has other effects cannot be concluded from our data. However, an increased NOSIII expression in 'cold' follicles during stimulation prior to the vasodilation is consistent with a role for NO in this process.

In conclusion, our data strongly suggest the existence of angio-follicular units in the thyroid with their own regulation. Angiogenic and vasodilative factors such as VEGF and NO are clearly involved in this regulation. However, additional studies are necessary to elucidate these regulatory mechanisms and to understand the formation of 'cold' follicles during ageing and 'cold' nodules during multinodular goiter formation.

\section{Acknowledgements}

The authors acknowledge the help of Dr F Casanas-Roux in the VEGF immunohistochemistry. This work has been supported by the FRSM (grants No 3.4590.92, 3.4506 .96 and 3.4516.98). Part of this work has been presented at the 25 th meeting of the European Thyroid Association, Athens, June 1998.

\section{References}

1 Folkman J, Watson K, Ingber D \& Hanahan D. Induction of angiogenesis during the transition from hyperplasia to neoplasia. Nature $198933958-61$. 
2 Wollman SH, Herveg JP, Zeligs JD \& Ericson LE. Blood capillary enlargement during the development of thyroid hyperplasia in the rat. Endocrinology $19781032306-2314$.

3 Denef JF, Haumont S \& Beckers C. Morphological changes in mice thyroid induced by iodine deficiency. Virchows Archives of Cell Pathology Series B 198032 191-199.

4 Denef JF, Haumont S, Cornette C \& Beckers C. Correlated functional and morphometric study of thyroid hyperplasia induced by iodine deficiency. Endocrinology 19811082352 2358.

5 Many MC, Denef JF \& Haumont S. Precocity of the endothelial proliferation during a course of rapid goitrogenesis. Acta Endocrinologica 1984105 487-491.

6 Viglietto G, Romano A, Manzo G, Chiappetta G, Paoletti I, Califano D, Galati MG, Mauriello V, Bruni P, Lago CT, Fusco A \& Persico MG. Upregulation of the angiogenic factors PIGF, VEGF and their receptors (Flt-1, Flk-1/KDR) by TSH in cultured thyrocytes and in thyroid gland of thiouracil-fed rats suggest a TSH-dependent paracrine mechanism for goiter hypervascularization. Oncogene 199715 2687-2698.

7 Wang JF, Milosveski V, Schramek C, Fong GH, Becks GP \& Hill DJ. Presence and possible role of vascular endothelial growth factor in thyroid cell growth and function. Journal of Endocrinology 1998 157 5-12.

8 Logan A, Black EG, Gonzalez AM, Buscaglia M \& Sheppard MC Basic fibroblast growth factor: an autocrine mitogen of rat thyroid follicular cells? Endocrinology 1992130 2363-2372.

9 Becks GP, Logan A, Phillips ID, Wang JF, Smith C, DeSousa D \& Hill DJ. Increase of basic fibroblast growth factor (FGF) and FGF receptor messenger RNA during rat thyroid hyperplasia: temporal changes and cellular distribution. Journal of Endocrinology 1994 $142325-338$.

10 Patel VA, Hill DJ, Eggo MC, Sheppard MC, Becks GP \& Logan A. Changes in the immunohistochemical localisation of fibroblast growth factor-2, transforming growth factor-1 and thrombospondin-1 are associated with early angiogenic events in the hyperplastic rat thyroid. Journal of Endocrinology $1996148485-$ 499.

11 Thompson SD, Franklin JA, Watkinson JC, Verhaeg JM, Sheppard MC \& Eggo MC. Fibroblast growth factors 1 and 2 and fibroblast growth factor receptor 1 are elevated in thyroid hyperplasia. Journal of Clinical Endocrinology and Metabolism 1998831336 1341.

12 Sheflin LG, Fucile NW, Ozawa S \& Spaulding SW. Thyroxine increases the levels of epidermal growth factor messenger ribonucleic acid (EGF mRNA) in the thyroid in vivo, as revealed by quantitative reverse transcription polymerase chain reaction with internal control EGF mRNA. Endocrinology 1993132 2319-2324.

13 Logan A, Smith C, Becks GP, Gonzalez AM, Phillips ID \& Hill DJ. Enhanced expression of transforming growth factor-1 during thyroid hyperplasia in rats. Journal of Endocrinology 1994141 45-57.

14 Colin I, Berbinschi A, Denef JF \& Ketelslegers JM. Detection and identification of endothelin-1 immunoreactivity in rat and porcine thyroid follicular cells. Endocrinology 1992130544 546.

15 Colin IM, Selvais PL, Rebai T, Maiter DM, Adam E, vandenHove MF, Ketelslegers JM \& Denef JF. Expression of the endothelin-1 gene in the rat thyroid gland and changes in its peptide and mRNA levels in goiter formation and iodine-induced involution. Journal of Endocrinology 1994143 65-74.

16 Colin IM, Nava E, Toussaint D, Maiter DM, vandenHove MF, Lüscher TF, Ketelslegers JM, Denef JF \& Jameson JL. Expression of nitric oxide synthase isoforms in the thyroid gland: evidence for a role of nitric oxide in vascular control during goiter formation. Endocrinology 1995136 5283-5290.

17 Colin IM, Kopp P, Zbären J, Häberli A, Grizzle WE \& Jameson JL. Expression of nitric oxide synthase III in human thyroid follicular cells: evidence for increased expression in hyperthyroidism. European Journal of Endocrinology 1997136 649-655.

18 Tode B, Serio M, Rotella CM, Galli G, Franceschelli F, Tanini A \& Toccafondi R. Insulin-like growth factor-I: autocrine secretion by human thyroid follicular cells in primary culture. Journal of Clinical Endocrinology and Metabolism 198969 639-647.

19 Pekary AE, Berg L, Wang J, Lee P, Dubinett SM \& Hershman JM. TNF- $\alpha$, TSH and aging regulate TGF- $\beta$ synthesis and secretion in FRTL-5 rat thyroid cells. American Journal of Physiology 1995268 R808-R815.

20 Taylor AH, Millatt LJ, Whitley G, Johnstone AP \& Nussey SS. The effect of basic fibroblast growth factor on the growth and function of human thyrocytes. Journal of Endocrinology 1993136 339344.

21 Studer H, Forster R, Conti A, Kohler H, Haeberli A \& Engler H. Transformation of normal follicles into thyrotropin-refractory 'cold' follicles in the aging mouse thyroid gland. Endocrinology $19781021576-1586$.

22 Tamura S \& Fujita H. Fine structural aspects on the 'cold' follicles in the aged mouse thyroid. Archivum Histologicum Japonicum 1981 44 177-188.

23 Mestdagh C, Many MC, Halpern S, Briançon C, Fragu P \& Denef JF. Correlated autoradiographic and ion-microscopic study of the role of iodine in the formation of 'cold' follicles in young and old mice. Cell and Tissue Research 1990260 449-457.

24 Weibel ER, Kistler GS \& Scherbe WR. Practical stereological methods for morphometric cytology. Journal of Cell Biology 1966 $3023-28$.

25 Denef JF, Cordier AC, Mesquita M \& Haumont S. The influence of fixation procedure, embedding medium, and section thickness on morphometric data in thyroid gland. Histochemistry 197963 163-171.

26 Imada M, Kurosumi M \& Fujita H. Three-dimensional aspects of blood vessels in thyroids from normal, low iodine diet-treated, TSH-treated, and PTU-treated rats. Cell and Tissue Research 1986 245 291-296.

27 Ericson LE \& Wollman SH. Ultrastructural aspects of capillary fusion during the development of thyroid hyperplasia. Journal of Ultrastructure Research 198072 300-315.

28 Smeds S \& Wollman SH. ${ }^{3} \mathrm{H}$-Thymidine labeling of endothelial cells in thyroid arteries, veins, and lymphatics during thyroid stimulation. Laboratory Investigation 198348 285-291.

29 Gerber H. Peter HJ \& Studer H. Age-related failure of endocytosis may be the pathogenic mechanism responsible for 'cold' follicle formation in the aging mouse thyroid. Endocrinology 1987120 $1758-1764$.

30 Nathan C \& Xie QW. Nitric oxide synthases: roles, tolls and controls. Cell 199478 915-918.

31 Senger DR, Galli SJ, Dvorak AM, Peruzzi CA, Harvey VS \& Dvorak HF. Tumor cells secrete a vascular permeability factor that promotes accumulation of ascites fluid. Science 1983219 983-985.

32 Breier G, Albrechts U, Sterrer S \& Risau W. Expression of vascular endothelial growth factor during embryonic angiogenesis and endothelial cell differentiation. Development 1992114 521-532.

33 Roberts WG \& Palade GE. Increased microvascular permeability and endothelial fenestrations induced by vascular endothelial growth factor. Journal of Cell Science 1995108 2369-2379.

34 Esser S, Wolburg K, Wolburg H, Breier G, Kurzchalia T \& Risau W. Vascular endothelial growth factor induces endothelial fenestrations in vitro. Journal of Cell Biology 1998140 947-959.

35 Lamas S, Marsden PA, Li GK, Tempst P \& Michel T. Endothelial nitric oxide synthase: molecular cloning and characterization of a distinct constitutive enzyme isoform. Biochemistry 199289 6348-6352.

Received 2 August 1999

Accepted 29 December 1999 